\title{
A POLÍTICA DE EDUCAÇÃO EM TEMPO INTEGRAL NO ENSINO MÉDIO DO ESTADO DO ACRE: BASES POLÍTICO-IDEOLÓGICAS QUE ORIENTAM O PROGRAMA ${ }^{1}$
}

\author{
THE FULL-TIME EDUCATION POLICY IN ACRE STATE HIGH SCHOOL: \\ POLITICAL-IDEOLOGICAL BASIS GUIDING THE PROGRAM
}

\section{LA POLÍTICA DE EDUCÁCION A TIEMPO COMPLETO EN LA ESCUELA SECUNDARIA DEL ESTADO DEL ACRE: BASES POLÍTICO-IDEOLÓGICA QUE GUÍA EL PROGRAMA}

Anderson Pereira Evangelista ${ }^{2}$ Lúcia de Fátima Melo ${ }^{3}$ Mark Clark Assen de Carvalho ${ }^{4}$

\begin{abstract}
RESUMO
A polêmica Reforma do Ensino Médio materializada na Lei $\mathrm{n}^{\circ} 13.415$ de 2017, e gestada no governo de Michel Temer (MDB) desdobra-se em políticas educacionais no contexto dos Estados que compõem a federação. Seus princípios encontram-se enraizados em uma perspectiva de Estado e de sociedade que ao que tudo indica visa atender as exigências econômicas e do mercado, numa concepção de educação utilitarista e mercadológica. Este artigo busca revelar as bases político-ideológicas do Programa de Educação em tempo Integral no Ensino Médio que vem sendo desenvolvido no âmbito da Rede Estadual de Educação do Estado do Acre (Lei no 3.366 de 2017), na tentativa de compreender como esta política se articula com que está posto na Reforma do Novo Ensino Médio, buscando contribuir com o debate em torno deste complexo objeto que é o Ensino Médio no Brasil. A reflexão não se esgota, mas convida a pensar em uma direção menos ingênua e mais reflexiva.
\end{abstract}

PALAVRAS-CHAVE: Reforma do Ensino Médio; Educação em Tempo Integral; Política Educacional.

Submetido em: 13/08/2019 - Aceito em: 17/08/2019 - Publicado em: 31/08/2019.

${ }^{1}$ Artigo teórico-reflexivo suscitado no âmbito da disciplina Estado, Políticas Públicas e Educação, componente curricular da Linha de Pesquisa Gestão e Política Educacional do Programa de Pós-Graduação em Educação da Universidade Federal do Acre-PPGE/UFAC.

${ }^{2}$ Mestrando do Programa de Pós-Graduação em Educação da Universidade Federal do Acre (PPGE-UFAC) (2018-2020).Licenciado em Educação Física pela Universidade Federal do Acre (2014-2018).

${ }^{3}$ Doutora em Educação: conhecimento e inclusão social pela UFMG. Professora do Programa de Pós-Graduação em Educação da Universidade Federal do Acre (PPGE/UFAC).

${ }^{4}$ Doutor em Educação: História ,Política e Sociedade pela PUC-SP. Professor do Programa de Pós-Graduação em Educação da Universidade Federal do Acre (PPGE/UFAC). 


\section{ABSTRACT}

The controversial High School Reform materialized in law $\mathrm{n}^{\circ} 13.415$ of 2017, and carried out under the government of Michel Temer (MDB) unfolds in educational policies in the context of the states that make up the federation. Its principles are rooted in a perspective of state and society that apparently aims to meet the economic and Market demands, in a conception of utilitarian and Market education. This article seeks to reveal the politicalideological basis of the Full-time High School Education Program that has been developed within the State of Acre Education Netwoork (Law n 3.366 of 2017), in na attempt to understand how this policy is implemented articulates with what is in the New High School Reform, seeking out to contribute to the debate around this complex object that is the High School in Brasil. Reflection does not end, but invites thinking in a less and more reflective direction.

KEYWORDS: High School Reform; Full time Education; Educational Politics.

\section{RESUMEN}

La controvertida reforma de la escuela secundaria se materializó en la Ley N ${ }^{\circ} 13.415$ de 2017, y se llevó a cabo bajo el gobierno de Michel Temer (MDB), se desarrolla en las políticas educativas en el contexto de los estados que componen la federación. Sus principios se basan en una perspectiva del estado y la sociedad que aparentemente apunta a satisfacer las demandas económicas y de mercado, en una concepción de la educación utilitaria y de mercado. Este artículo busca revelar la base político-ideológica del Programa de Educación de Escuela Secundaria a tiempo completo que se ha desarrollado dentro de la Red de Educación del Estado del Estado de Acre (Ley N ${ }^{\circ} 3666$ de 2017), en un intento por comprender cómo esta política se articula con lo que está en la Nueva Reforma de la Escuela Secundaria, buscando contribuir al debate en torno a este complejo objeto que es la Escuela Secundaria en Brasil. La reflexión no termina, sino que invita a pensar en una dirección menos ingenua y más reflexiva.

PALABRAS CLAVE: Reforma de la escuela secundaria; Educación a tiempo completo; Política educativa.

\section{INTRODUÇÃO}

Este artigo tem como finalidade trazer contribuição às discussões em torno dos desdobramentos oriundos da mais recente reforma do Ensino Médio no Brasil. O seu foco principal é analisar o contexto de influência que incidiu sobre a formulação da política de Educação em Tempo Integral no Ensino Médio do Estado do Acre. O texto assume um movimento que parte de uma perspectiva macro para revelar as bases político-ideológicas nas quais ancora-se o programa. Por assumir um posicionamento crítico perante os fatos, a escrita se distancia de um olhar ingênuo e entusiasta, buscando compreender de onde se origina tal política, evidenciando suas reais intencionalidades, uma vez que estas fundamentam-se ao que nos parece em um ideário de sociedade que procura atender bem mais os interesses da classe dominante.

O momento histórico e político em que é gestada a reforma do Ensino Médio é subsequente ao golpe empreendido à Presidenta da República Dilma Rousseff (PT) em 31 de 
Agosto de 2016. Após exaustivo processo arquitetado por meio de um conluio, a presidenta é destituída e assume o seu vice Michel Temer (MDB), abertamente favorável ao golpe. Ao tornar-se chefe do executivo Temer inicia sua política de austeridade econômica ${ }^{5}$. Em seu pacote bastante identificado com uma política neoliberal estava a Emenda Constitucional $n^{\circ} 95$ de 2016 que congelou os gastos públicos por 20 anos. Era apenas o começo da agenda reformista em curso que advoga explicitamente os interesses de mercado.

Em sintonia com as exigências do mercado cada vez mais globalizado e efêmero, o governo Temer pressionado pelo empresariado que determina a pauta educacional no Brasil (FREITAS, 2012; MARTINS, 2016) arbitrariamente decide reformar o polêmico ensino médio, de maneira unilateral. De acordo com Motta e Frigotto (2017, p. 357): “[...] essa "reforma" imprime, sem reservas ou busca de consenso, a insanável contradição ético-política do pensamento e da moral capitalista do tipo dependente: perversamente autoritário". Dito isto, é importante compreendermos inicialmente, o 'modus operandi' que culminou nesta reforma; para então chegarmos a política de Educação em Tempo Integral no Ensino Médio do Estado do Acre.

\section{URGENTE, COMPROMISSADA COM O MERCADO, IMPOSITIVA} FLEXIBILIZADORA: a reforma do ensino médio via Medida Provisória

Por meio de uma Medida Provisória (MP n 746/2016) o governo inaugura a mais nova reforma do Ensino Médio. Já nos primeiros meses do governo Temer, a Medida Provisória é instituída, sendo discutida com urgência pelo legislativo e transformada na Lei $n^{\circ}$ 13.415/2017 em tempo recorde, sem ampla participação dos atores diretamente implicados no processo (MOTTA e FRIGOTTO, 2017; FERRETI e SILVA, 2017; LINO, 2017; GONÇALVES, 2017). A urgência dessa reforma se explica pela necessidade de se adequar ao que estabelece o mercado internacional, como esclarecem Motta e Frigotto (2017, p. 357):

\footnotetext{
5"A famigerada austeridade econômica tornou-se palatável pelo eufemismo do "ajuste fiscal" e foi apontada como a única saída para o colapso segundo a cartilha liberal, sendo exportada para o mundo quando os países se viram diante do tsunami causado pela crise" (BLYTH, 2018).
} 


\begin{abstract}
Segundo dirigentes do Ministério da Educação (MEC), a reforma do Ensino Médio é urgente porque é necessário destravar as barreiras que impedem o crescimento econômico. E a educação, principalmente a educação profissional, é um fator importante para a retomada do crescimento econômico, uma vez que o investimento em capital humano potencializa a produtividade. Nessa perspectiva, no âmbito da educação, seriam aspectos necessários para elevar as condições de competitividade do Brasil no mercado internacional: o investimento na melhoria da qualidade do Ensino Médio, até mesmo com o aumento da jornada escolar, visando melhores alcances no desempenho escolar; a reestruturação do currículo, ajustando-o às mudanças no mundo do trabalho, em conformidade com a suposta educação do século XXI; a ampliação do número de vagas; e a contenção da evasão escolar.
\end{abstract}

De forma bem explícita o governo declara o que pretende com a reforma. Bastante compromissada com os interesses mercadológicos a reforma do ensino médio segue um mecanismo naturalizado nas sociedades capitalistas. Para Gonçalves (2017, p. 140) "A influência do modo de produção nas políticas sociais e educacionais não é algo novo. $\mathrm{O}$ capitalismo, a cada crise, procura se reinventar para garantir sua manutenção e para isso são implementadas reformas em diferentes esferas da sociedade".

Com base em um movimento mais amplo que se verifica desde a década de 1970, reformas como a do ensino médio advém dos pressupostos político-organizacionais presentes na Nova Gestão Pública (NGP) que "surge em contraposição à Administração Pública, buscando influenciar novos modos não só de organizar e gerir a coisa pública, mas também novos modos de governo, já que ela interfere nos objetivos da ação política" (OLIVEIRA, DUARTE e CLEMENTINO, 2017, p. 711).

Para além disto, as reformas estão discursivamente e pragmaticamente alinhadas com uma perspectiva de Estado e seus fundamentos, como destaca Costa (2019, p. 161):

As contrarreformas no papel do Estado e da educação, a partir da década de 1980, têm sido frequentemente tratadas como parte de um conjunto de valores de inspiração neoliberal e neoconservadora, baseados no mercado, com vistas a adequar a educação à competitividade internacional.

A inspiração neoliberal e neoconservadora apontada pela autora é discutida por Apple (2002), quando analisa o fenômeno de "viragem para a direita". Protagonizado por uma aliança consensual que reúne 4 grandes grupos e incidem diretamente na política educacional, são eles: neoliberais, neoconservadores, populistas autoritários e parte da classe média profissional. Apple acrescenta ainda que os neoliberais se constituem no grupo que capitaneia a viragem. 
Estes defendem estritamente a racionalidade econômica, tornando os alunos apenas capital humano destinados ao mercado (APPLE, 2002).

Quanto ao Estado $^{6}$ onde se opera as reformas este se posiciona no mercado internacional como o agente mediador/negociador que converge suas ações ao aspecto mais voltado para o econômico. Para tanto assume a função de preparar seu capital humano (BALL, 2004). Discutindo o investimento em capital humano enquanto justificativa da reforma, Motta e Frigotto (2017, p. 358) avaliam que:

A ideia de investimento em capital humano como motor de desenvolvimento econômico é uma determinada concepção de formação humana nos marcos restritos das necessidades de mercado. Enfatiza os conhecimentos úteis que o estudante deve adquirir para impulsionar a produtividade dos setores econômicos, a fim de potencializar a competitividade nos mercados local e internacional, ou para criar condições de empregabilidade, isto é, desenvolver habilidades e competências que potencializem a inserção do indivíduo no mercado de trabalho.

Neste sentido, é possível verificar a forma como tudo isso se articula a reforma do ensino médio ao tornar central a preparação do jovem para o mercado de trabalho. Com o "novo ensino médio" mostra-se o real interesse dos reformadores empresariais da educação que é destinar a classe trabalhadora uma formação profissional em detrimento da humanística, perpetuando-se o status quo.

Herdeiro da tradição dual, qual seja, de encaminhar os jovens para destinos desenhados a partir do berço, elemento característico de uma sociedade de quasecastas, o ensino médio encarnou historicamente (como escola secundária ou como $2^{\circ}$ grau) a lógica da profissionalização para os jovens das camadas populares e a lógica propedêutica para os poucos destinados ao ensino superior (MOLL, 2017, p. 62).

Importante desvelarmos quem são os reformadores que advogam as exigências de mercado, com o objetivo comum de manter-se na posição superior, movendo as peças do jogo

\footnotetext{
${ }^{6}$ Compreendemos o Estado neste texto a partir das contribuições de Ferraz (2016) ao entender o Estado Moderno como "um lócus privilegiado de poder e uma função gerencial, reguladora ou política de fixação dos parâmetros de igualdade, assim como das ações para melhor promovê-la" (p. 25).
}

${ }^{7}$ Ver Freitas (2012) 
político, fazendo lobbying ${ }^{8,}$ e se auto intitulando especialistas em educação, como podemos ver com Gonçalves (2017, p.141):

Para organizar a Reforma do Ensino Médio, os interlocutores do Ministério da Educação não foram universidades, pesquisadores, professores e estudantes, mas, sim, empresários, através de organizações como o Instituto Alfa Beta, Sistema S, Instituto Unibanco, Instituto Ayrton Senna, Fundação Itaú, entre outros.

O empresariado que influencia a pauta educacional no Brasil, e orientou a formulação da reforma do ensino médio compõe o famoso Todos Pela Educação (TPE). Segundo Martins (2016) o TPE “denomina-se uma aliança nacional apartidária composta pela sociedade civil, pela iniciativa privada e por organizações sociais de educadores e de gestores públicos da educação”. A autora ainda aponta que:

Por seus integrantes atuarem com a intenção de influenciar políticas públicas através da produção e difusão de conhecimentos, o TPE também pode ser considerado um thinktank da educação, cujo conceito "surgiu durante a Segunda Guerra Mundial, nos Estados Unidos, como analogia a um lugar onde as conversas não podem ser interceptadas (tank) e nos quais experts civis e militares traçam estratégias militares e planos de invasão (think) [...] (MARTINS, 2016, p. 13).

Enquanto especialistas que pensam a educação e tem as "melhores soluções" para mudar a realidade reduzida ao aspecto econômico, o Todos Pela Educação alinha-se a uma agenda de internacionalização das políticas educacionais, movimento global orientado por organismos multilaterais como o Banco Mundial e a Organização para Cooperação e Desenvolvimento Econômico - OCDE (SHIROMA, GARCIA e CAMPOS, 2011; MARTINS, 2014).

O aspecto impositivo da reforma do Ensino Médio já começa quando parte do executivo através do poder conferido a este via Medida Provisória, o que permite afirmar que a reforma anunciada assume características unilateral. De acordo com Lino (2017, p. 77) "O uso da medida provisória caracteriza uma forma autoritária de legislar, que sinaliza o desprezo pelo necessário diálogo acadêmico e legislativo, típico de um regime de exceção”.

\footnotetext{
${ }^{8}$ A palavra lobby significa, em inglês, antesala, vestíbulo, saguão. Por extensão, o lugar onde ficavam as pessoas que procuravam influenciar as autoridades e/ou políticos e que acabou por designar a ação de profissionais ou grupos que buscavam exercer pressões, muitas vezes legais, para que fossem aprovados projetos ou medidas em benefício daqueles que são por eles representados. (BORIN, 1988 apud OLIVEIRA, 2005, p. 30).
} 
A arbitrariedade do governo diante da polêmica pauta que é o ensino médio, historicamente marcado por embates e disputas (KRAWCZYCK, 2014; SILVA e SCHEIBE, 2017), fere uma característica essencial do processo político no Estado moderno, que é a controvérsia, discutida por Ferraz que se baseia em Poggi (1981) quando diz que "[...] a controvérsia não é simples concessão às vozes opositoras, mas elemento constitutivo, e não menos importante, para o regular funcionamento do processo político do Estado Moderno" (FERRAZ, 2016).

O silenciamento de importantes vozes no processo de construção desta reforma, a caracteriza como simples, equacional e vazia no tocante aos sujeitos desse processo. Suas subjetividades são esvaziadas, assumindo uma identidade padrão-mercado: robotizada. Motta e Frigotto (2017) declaram que pela reforma ser "fetichizada pelo determinismo tecnológicoinovador, [...] não há sujeitos históricos, e sim alunos abstratos, jovens trabalhadores deslocados de suas condições objetivas e materiais reais".

Urgente, compromissada com o mercado e impositiva, esta reforma veio flexibilizar o currículo do ensino médio (KRAWCZYCK e FERRETI, 2017). De acordo com os autores "a ideia de flexibilização vem sendo utilizada nas últimas décadas para se opor a uma estrutura estatal de proteção do trabalho e de proteção social". Para tanto empreendem-se reformas flexibilizadoras desde as relações de trabalho ao currículo (p.36).

Dito isto, é importante se fazer a seguinte pergunta: Quais as estratégias presentes no texto da política materializam a flexibilização? Ainda com Krawczyck e Ferreti (2017), veremos que as mudanças anunciadas voltam-se ao tempo escolar, ou seja, ao tempo de permanência do aluno no tempo espaço da escola. Na diversificação da estrutura curricular que será organizada pela Base Nacional Comum Curricular (BNCC) e pelos Itinerários formativos. E o mais polêmico ponto que é a flexibilização do trabalho docente, quando se admite que profissionais não-docentes com notório saber tenham a incumbência das atividades específicas do professor.

A interesse da reflexão que tem se construído através do texto, nos deteremos ao elemento da reforma que é a ampliação do tempo escolar, que vai se materializar no programa de Educação em Tempo Integral no Ensino Médio da rede pública de ensino do Estado do Acre, o que discutiremos a seguir. 


\section{A POLÍTICA DE EDUCAÇÃO EM TEMPO INTEGRAL NO ENSINO MÉDIO DO ESTADO DO ACRE: compreendo suas bases político-ideológicas.}

A lei no 13.415/2017 além de trazer as alterações à Lei de Diretrizes e Bases da Educação Nacional (LDB 9394/96), à leis que regulamentam o Fundo de Manutenção e Desenvolvimento da Educação Básica e de Valorização dos Profissionais da Educação (FUNDEB), alterando a CLT ${ }^{9}$ e alguns decretos diretamente relacionados à reforma, ainda institui a Política de Fomento à implementação de Escolas de Ensino Médio em Tempo Integral (BRASIL, 2017).

Analisando a lei que instituiu o Novo Ensino Médio, Silva e Boutin (2018) relatam que esta veio retomar a agenda da educação integral no Brasil, que vinha sendo representada pelo Programa Mais Educação ${ }^{10}$; mas que agora fora deslocada para o Ensino Médio. Neste ponto, se faz necessário compreendermos a concepção de Educação Integral para além do que está posto. Segundo Moll (2012, p. 129):

O debate da educação integral no Brasil, compreendida como educação escolar de dia inteiro, constituída e enriquecida por significativas possibilidades formativas, teve no século XX dois marcos significativos: as Escolas-Parque/Escolas-Classe concebidas por Anísio Teixeira nos anos de 1940/1960, e os Centros Integrados de Educação Pública (CIEPs) idealizados por Darcy Ribeiro nos anos de 1980/1990.

A autora destaca ainda que o projeto original da Educação Integral se tangenciava do simples aumento da jornada escolar. A ampliação do tempo de permanência do aluno na escola

\footnotetext{
${ }^{9}$ A Consolidação das Leis Trabalhistas foi alterada pela Lei $\mathbf{N}^{\mathbf{0}} \mathbf{1 3 . 4 6 7}$ de 13 de Julho de 2017 por meio da Reforma Trabalhista realizada ainda no Governo Temer.

10 “A Portaria Interministerial n ${ }^{\circ}$ 17, de 24 de abril de 2007 instituiu o Programa Mais Educação com a parceria formal dos Ministérios do Desenvolvimento Social e Combate à Fome, da Cultura, do Esporte e o da Educação. O Programa Dinheiro Direto na Escola, do Fundo Nacional de Desenvolvimento da Educação (PDDE/FNDE) operacionalizou o financiamento de suas ações desde 2008, desencadeando o processo de adesão das escolas e redes de ensino. O Decreto $n^{\circ} 7.083 / 2010$ (Brasil, 2010) regulamentou essa estratégia para induzir a ampliação do tempo diário de permanência de crianças, adolescentes e jovens na escola em atividades educativas coordenadas pela escola" (LECLERE, 2012, p.307).
} 
se faz necessário sim, mas os temposespaços destinados ao processo de construção da aprendizagem, compromissada com os múltiplos saberes precisam ser adequados e permitir que a Educação Integral seja viável (2012, p. 129). Mas a realidade da reforma em questão é esclarecida por Silva e Boutin (2018, p. 525) quando colocam que:

\begin{abstract}
A atual proposta de reforma do ensino médio, aparentemente, trata-se de mais uma política na agenda da educação integral que visa muito mais a necessidade de ampliar o tempo do que de ampliar as possibilidades educativas comprometidas com a formação mais completa do educando, demonstrando que o que se deseja é, na verdade, um aluno por mais tempo na escola.
\end{abstract}

Mais tempo na escola para formar capital humano na perspectiva do mercado, redirecionando o sentido da educação integral para que esta atenda as exigências da "mão invisível" que tudo controla. De acordo com Libâneo (2016) as políticas educacionais implementadas no Brasil seguindo orientações dos organismos internacionais como a Unesco e o Banco Mundial têm causado o desfiguramento da escola e do conhecimento escolar.

Para exemplificar este processo o autor analisa a proposta de escola em tempo integral sugerida pelo MEC (Ministério da Educação), através do documento Educação Integral (BRASIL, 2009). Ao decorrer da análise crítica o autor vai revelando de que forma a racionalidade econômica é pulverizada em ações que explicitamente voltam-se para amenizar a pobreza e os conflitos sociais. Onde na verdade o objetivo oculto é forjar valores e atitudes, nas palavras de Gramsci, nos subalternos para que estes participem da sociedade em seus moldes econômico e social.

Seguindo o entendimento de Libâneo (2016) é possível inferirmos de que forma se vê e se utiliza a educação em tempo integral, seguramente para atender as demandas da ordem vigente que é mercadológica. E sob quais bases articula-se o Programa de Educação em Tempo Integral do Ensino Médio do Estado do Acre?

Exarada em Fevereiro de 2017 a célere Reforma do Ensino Médio em profícua rapidez repercute no contexto local do Estado do Acre. O governo do Estado ao momento ocupado pelo Partido dos Trabalhadores, imprime de forma unilateral o Programa de Educação em Tempo Integral no Ensino Médio. Já em 2017 inicia por intermédio de Escolas-piloto o sistema de integralidade, a reforma do ensino médio prevê "a elevação da carga horária mínima anual de 


\section{Revista Docência e Cibercultura}

800 horas para 1.400 horas, uma grande elevação de 75\%" (AMARAL, 2017, p. 93). Em Março daquele ano, 7 (sete) escolas localizadas na capital Rio Branco, são escolhidas para iniciar o processo de implementação.

Em 2018, já com o Programa regulamentado em Lei, esse é expandido para o interior do Estado, especificamente nos municípios de Cruzeiro do Sul, Tarauacá e Brasiléia. As 10 escolas de ensino médio que funcionam em tempo integral atualmente são: Instituto Educacional Lourenço Filho (IELF), Glória Perez, Humberto Soares, José Ribamar Batista (EJORB), Escola Jovem Boa União, Sebastião Pedrosa, Colégio Estadual Armando Nogueira (CEAN), todas localizadas na capital Rio Branco. Craveiro Costa, em Cruzeiro do Sul, Djalma da Cunha Batista, em Tarauacá e José Kairala, em Brasiléia.

A lei ${ }^{\circ} 3.366$ de 27 de Dezembro de 2017, denomina as escolas de tempo integral como Escolas Jovens, assim entendidas no Art. $3^{\circ}$ da lei:

I - escolas públicas de ensino médio em tempo integral, denominadas Escolas Jovens: unidades escolares com conteúdos pedagógicos, métodos didáticos, gestão curricular e administrativa próprios, com regulamentação prevista em normas específicas, com parecer e resolução próprias, do Conselho Estadual de Educação - CEE/AC e, no que couber, na legislação estadual pertinente à educação.

Com base em informações coletadas no site da Secretaria Estadual de Educação, Cultura e Esporte (SEE), o investimento financeiro feito em 2017 gira em torno dos R \$ 21 milhões dos $\mathrm{R}$ \$ 28 milhões de recursos destinados para a escola em tempo integral, um total de $75 \%$ do montante. E nos perguntamos, de onde vem os recursos em um contexto de congelamento dos gastos públicos via Emenda Constitucional n ${ }^{\circ} 95$ de 2016? De acordo com Amaral (2017, p.94):

A Política de Fomento à Implementação de Escolas de Ensino Médio em Tempo Integral (Política de Fomento) "prevê o repasse de recursos do Ministério da Educação para os Estados e para o Distrito Federal pelo prazo de dez anos por escola" (BRASIL. LEI No 13.415, parágrafo único, Art. 13, 2017). A Política de Fomento estipula que haverá a alocação de recursos financeiros do MEC, via Fundo Nacional do Desenvolvimento da Educação (FNDE), diretamente para os estados e o Distrito Federal, por escola que tenha formalizado um Termo de Compromisso a ser assinado.

Este mesmo autor discute a contradição inferida quando o governo anuncia os altos investimentos no fomento à implementação de escolas de ensino médio em tempo integral; em 
um contexto de austeridade econômica. Uma vez que para além do compromisso assumido com o novo ensino médio, as metas do PNE (Plano Nacional de Educação - 2014-2024) precisam ser atingidas. Conclui ao final da análise que os investimentos não se efetivarão nem para o PNE quiçá para a política de fomento, em razão do desmonte e sucessivas retiradas de direitos (AMARAL, 2017).

Analisado o programa em aspectos gerais, passaremos agora ao plano de fundo, as bases que o sustentam e o faz ser, revelando as convergências ao mercado e a sintonia com a reforma do ensino médio, sendo seu fruto.

Observemos a comum característica entre a Reforma (Lei n $\left.{ }^{\circ} 13.415 / 2017\right)$ e o Programa de Educação em Tempo Integral no Ensino Médio do Acre (Lei no 3.366/2017) quanto ao modus operandi. A ação parte do executivo (unilateral), uma vez que a lei que regulamenta o programa só é aprovada em Dezembro de 2017; quando este já estava sendo implementado. E o que motiva a celeridade da criação do Programa? O estudo de Amaral (2017) nos fornece uma pista para responder a essa questão. Segundo o autor "somente poderão acessar os recursos financeiros da Política de Fomento aquelas escolas que tenham iniciado a oferta de atendimento em tempo integral a partir do dia 16 de fevereiro de 2017”. Com isto, pensamos ser esta uma possível resposta.

Outra resposta diz respeito ao IDEB (Índice de Desenvolvimento da Educação Básica). Pelo insucesso nas avaliações externas "o Ensino Médio vem se tornando um dos grandes desafios do ensino público acriano neste aspecto, uma vez que, tanto na versão 2013, quanto na de 2015, sequer a meta do MEC foi alcançada" (MELO e TORRES, 2017, p. 818). No art. $6^{\circ}$ da lei que instituiu o programa está assinalada uma incumbência específica das Escolas Jovens que atenda aos testes estandardizados (AFONSO,2012), pois compete à estas escolas:

$\mathbf{V}$ - fomentar práticas focadas na elevação da proficiência dos estudantes de sorte a obter melhores resultados no Índice de Desenvolvimento da Educação Básica - IDEB e Índice de Desenvolvimento da Educação do Acre - IDEA, tanto no componente de fluxo/rendimento quanto no de aprendizagem/desempenho de acordo com as metas estabelecidas no plano de ação da SEE. (CONF. LEI No 3.366/2017).

Seguindo o que estabelece a reforma do Ensino Médio ao eleger disciplinas mais importantes que outras, sendo "obrigatórias durante todo o ensino médio somente as disciplinas 
Português, Matemática e Inglês (KRAWCZYCK e FERRETI, 2017, p. 37), fica estabelecido no texto da política que:

Art. $8^{\circ}$ A carga horária estabelecida na matriz curricular das Escolas Jovens será de, no mínimo, dois mil, duzentos e cinquenta minutos semanais, com um mínimo de trezentos minutos semanais de língua portuguesa, trezentos minutos semanais de matemática e quinhentos minutos semanais dedicados para atividades da parte diversificada.

O compromisso implícito de formar técnicos - operadores de máquinas - robotizados para o capital, se verifica ao ser destinados 600 minutos ao português e matemática, ou seja, 10 horas semanais no mínimo, o aluno terá de aulas das disciplinas-chave do currículo. Em detrimento de amplo conhecimento e consciência crítica da realidade, reconhecendo-se como sujeito histórico e autor de si (KRAWCZYCK e FERRETI, 2017).

Um outro fato mais ainda ligado ao mercado que merece destaque, é o assessoramento por empresas ou iniciativas privadas à educação em tempo integral. Segundo Frigotto (2013) "isso se efetiva pela adoção por prefeituras e estados de institutos privados para gerir os sistemas de ensino no conteúdo e no método e nos valores mercantis". No contexto do Programa de Educação em Tempo Integral do estado do Acre, o protagonista é o Instituto Natura ${ }^{11}$. A estreita relação público-privada enrreda sobre a "nova filantropia" e o "capitalismo social" ao pensar as "soluções de mercado" para problemas sociais e educacionais (BALL, 2014). O papel do Instituto Natura portanto, no centro da política em análise é propor receitas prontas de qualidade e eficiência na educação do seu lugar de fala, que é o mercado.

\section{CONSIDERAÇÕES FINAIS}

Nos limites deste artigo e pelo que foi dito até aqui é preciso afirmar que caminhar nas entrelinhas da polêmica reforma do Ensino Médio buscando compreender seu desdobramento

\footnotetext{
${ }^{11} \mathrm{O}$ Instituto diz em sua apresentação no site oficial que "a paixão pela educação é o que nos move desde a nossa criação, em 2010. Ao lado de uma rede parceiros, executamos e apoiamos projetos voltados à melhoria da educação brasileira, no Brasil e na América Latina, acreditando na transformação social por meio da educação equânime e de qualidade".
} 


\section{Revista Docência e Cibercultura}

que é o Programa de Educação em tempo Integral no Ensino Médio do Estado do Acre, revelando onde este se ancora, não é tarefa fácil.

O debate teórico reflexivo aqui construído veio somar com as discussões postas em torno deste objeto historicamente marcado, arena de disputa por hegemonia, e de uma concepção de sociedade enraizada no ideário dominante. Este que age em prol de sua manutenção no poder, inviabilizando a ascensão da classe trabalhadora, uma vez que esta é a força de trabalho que produz a riqueza e bens que é a ela negado o direito de usufruir. Nas palavras de Frigotto (2013) "O estigma colonizador e escravocrata da classe dominante brasileira produziu uma burguesia que não completou, em termos clássicos, a revolução burguesa e, como tal, não é nacionalista, mas associada ao grande capital".

Movendo-se em direção única que são seus interesses a classe dominante maquia de responsabilidade social, e amor pela educação a realidade que lhes favorece; adentrando os imaginários que naturalizam as desigualdades. A Reforma do Ensino Médio pensada no bojo da agenda neoliberal apresenta-se como uma fantasia através de sua propaganda, mas a realidade é um pesadelo, parafraseando Krawczyck (2017).

As bases político-ideológicas do Programa de Educação em tempo Integral no Ensino Médio, revelam como este está intimamente ligado à lógica de mercado, imprimida preliminarmente na lei 13.415 de 2017. Pensar a Educação Integral nos fundamentos de Anísio Teixeira e Darcy Ribeiro, onde os investimentos deveriam ser reais, para que os temposespaços de aprendizagem pudessem ser difusos, não é algo agradável para o mercado, que tudo reduz ao aspecto econômico.

Reforçamos que as discussões apresentadas neste artigo, dada a complexidade de fatores que atravessam essa política, nos impele a fazer maiores aprofundamentos baseados em estudos e pesquisas empíricas, o que ainda é bastante incipiente em contex to local.

\section{REFERÊNCIAS}

ACRE, Lei no 3.366 de 27 Dezembro de 2017. Institui o Programa de Educação Integral e as Escolas Jovens de ensino médio em tempo integral na rede pública de educação básica do Estado. Dez. 2017. 
AFONSO, Almerindo Janela. Para uma concetualização alternativa de accountability em educação. Educação \& Sociedade, v. 33, n. 119, p. 471-484, 2012.

AMARAL, Nelson Cardoso. O "novo" ensino médio e o PNE: haverá recursos para essa política? Retratos da Escola, v. 11, n. 20, p. 91-108, 2017.

APPLE, Michael W. Endireitar" a educação: as escolas e a nova aliança conservadora. Currículo sem fronteiras, v. 2, n. 1, p. 55-78, 2002.

BALL, Stephen J. "Nova" Filantropia, Capitalismo Social e Política Educacional. In: . Educação Global S.A: Novas redes políticas e o imaginário neoliberal. Ponta Grossa, 2014. p.115-150.

BALL, Stephen J. Performatividade, privatização e o pós-estado do bem-estar. Educação \& Sociedade, v. 25, n. 89, p. 1105-1126, 2004.

BRASIL. Lei $\mathbf{n}^{\mathbf{0}} \mathbf{1 3 . 4 1 5}$ de 16 de fevereiro de 2017. Altera as Leis nos 9.394, de 20 de dezembro de 1996, que estabelece as diretrizes e bases da educação nacional, e 11.494, de 20 de junho 2007, que regulamenta o Fundo de Manutenção e Desenvolvimento da Educação Básica e de Valorização dos Profissionais da Educação, a Consolidação das Leis do Trabalho CLT, aprovada pelo Decreto-Lei no 5.452, de 1o de maio de 1943, e o Decreto-Lei no 236, de 28 de fevereiro de 1967; revoga a Lei no 11.161, de 5 de agosto de 2005; e institui a Política de Fomento à Implementação de Escolas de Ensino Médio em Tempo Integral.

COSTA, Marilda de Oliveira. Contrarreformas, Nova Gestão Pública e relações públicoprivadas: mapeando conceitos, tendências e influências na educação. Revista Brasileira de Política e Administração da Educação-Periódico científico editado pela ANPAE, v. 35, n. 1, p. 159-179.

FERRAZ, Marcos. Estado, Política e Sociabilidade. In: SOUZA, Ângelo Ricardo de, GOUVEIA, Andréa Barbosa, TAVARES, Taís Moura (Orgs.). Políticas Educacionais: Conceitos e debates. Curitiba: Appris, 2016, p. 23-45.

FERRETI, Celso João; SILVA, Mônica Ribeiro da. Reforma do Ensino Médio no contexto da Medida Provisória No 746/2016: Estado, Currículo e disputas por hegemonia. Educação \& Sociedade, v. 38, n. 139, p. 385-404, 2017.

FREITAS, Luiz Carlos de. Os reformadores empresariais da educação: da desmoralização do magistério à destruição do sistema público de educação. Educação \& Sociedade, 2012.

FRIGOTTO, Gaudêncio. Ensino Médio e técnico profissional: disputa de concepções e precariedade. Le Monde Diplomatique Brasil, v. 6, n. 68, p. 28-29, 2013. 
GONÇALVES, Suzane da Rocha Vieira. Interesses mercadológicos e o "novo" ensino médio. Retratos da Escola, v. 11, n. 20, p. 131-145, 2017.

KRAWCZYCK, Nora. O Ensino Médio Flexibilizado: Uma reforma entre a fantasia da propaganda e o pesadelo da realidade. Palestra proferida no XXI Encontro Estadual de Supervisores do Magistério. 2017.

KRAWCZYK, Nora; FERRETTI, Celso João. Flexibilizar para quê? Meias verdades da "reforma". Retratos da Escola, v. 11, n. 20, p. 33-44, 2017.

LIBÂNEO, José Carlos. Políticas educacionais no Brasil: desfiguramento da escola e do conhecimento escolar. Cadernos de Pesquisa, v. 46, n. 159, p. 38-62, 2016.

LINO, Lucilia Augusta. As ameaças da reforma: desqualificação e exclusão. Retratos da Escola, v. 11, n. 20, p. 75-90, 2017.

MARTINS, Erika Moreira. Todos pela Educação? Como os empresários estão determinando a política educacional brasileira. Rio de Janeiro: Lamparina, 2016.

MELO, Lúcia de Fátima; TORRES, Mário Roberto Machado. A função de diretor de escola pública no estado do acre e sua política de formação e remuneração. Revista Brasileira de Política e Administração da Educação, v. 33, n 3, p. 811-833, set/dez. 2017.

MOLL, Jaqueline. A agenda da educação integral: compromissos para sua consolidação como política pública. In: (Org.).Caminhos da Educação Integral no Brasil: direito a outros tempos e espaços educativos. Porto Alegre: Penso, 2012. p.129-146.

MOLL, Jaqueline. Reformar para retardar: a lógica da mudança no EM. Retratos da Escola, v. 11, n. 20, p. 61-74, 2017.

MOTTA, Vânia Cardoso da; FRIGOTTO, Gaudêncio. Por que a urgência da reforma do ensino médio? Medida Provisória no 746/2016 (Lei n 13.415/2017). Educação \& Sociedade, v. 38, n. 139, p. 355-372, 2017.

OLIVEIRA, Dalila Andrade; DUARTE, Alexandre William Barbosa; CLEMENTINO, Ana Maria. A Nova Gestão Pública no Contexto Escolar e os Dilemas dos (as) diretores (as). Revista Brasileira de Política e Administração da Educação-Periódico científico editado pela ANPAE, v. 33, n. 3, p. 707-726, 2017.

SHIROMA, Eneida Oto; GARCIA, Rosalba Maria Cardoso; CAMPOS, Roselane Fátima. Conversão das "almas" pela liturgia da palavra: uma análise do discurso do movimento Todos pela Educação. In: BALL, Stephen J.; MAINARDES, Jefferson (Orgs.). Políticas educacionais: questões e dilemas. São Paulo: Cortez, 2011, p. 222-248. 
SILVA, Karen Cristina; BOUTIN, Aldimara Catarina. Novo ensino médio e educação integral: contextos, conceitos e polêmicas sobre a reforma. Educação (UFSM), v. 43, n. 3, p. 521-534, 2018 .

SILVA, Mônica Ribeiro da; SCHEIBE, Leda. Reforma do ensino médio: pragmatismo e lógica mercantil. Retratos da Escola, v. 11, n. 20, p. 19-31, 2017. 